\title{
Zirconium Oxide Nanoparticles as an Efficient Catalyst for three-component Synthesis of Pyrazolo $[1,2-a][1,2,4]$ triazole-1,3-diones Derivatives
}

\author{
HOSSEIN ANARAKI-ARDAKANI* and TAYEBE HEIDARI-RAKATI
}

Department of Chemistry, Mahshahr Branch, Islamic Azad University, Mahshahr, Iran

${ }^{*}$ Corresponding author E-mail: hosseinanaraki @ yahoo.com

http://dx.doi.org/10.13005/ojc/320339

(Received: April 22, 2016; Accepted: June 13, 2016)

\begin{abstract}
An efficient and green protocol for the synthesis of pyrazolo[1,2-a][1,2,4]triazole-1,3-diones derivatives by one pot, three component coupling reaction of aromatic aldehyde, malononitrile, and 4-phenylurazole has been developed using $\mathrm{ZrO}_{2}$ nanoparticles (NPs) as the catalyst. The procedure is formed in high yields, short reaction time and an environmentally friendly specificity.
\end{abstract}

Keywords: multicomponent reaction, $\mathrm{ZrO}_{2}$ nanoparticles (NPs), solvent-free, Malononitrile.

\section{INTRODUCTION}

Multi-component reactions have been attracting much interest from synthetic chemists because they provide simple one-pot routs for the synthesis of complex molecules from simple and easily available starting materials. These processes are single-step and don't require separation and purification of intermediates and so save time, energy and raw materials. ${ }^{1}$

Recently, heterogeneous catalysts have attracted the attention of researchers due to their economic and industrial significance and published reports indicate that they scored over homogeneous catalysts. Among these, nanoscale heterogeneous catalysts are highly preferred as they offer high surface area and low-coordinated sites, which are responsible for the higher catalytic activity, ${ }^{2-4}$ having the advantage of easy product purification and reusability of the catalyst.

$\mathrm{N}$-Heterocycles receive considerable attention in the literature as a consequence of their exciting biological properties and their role as pharmacophores. ${ }^{5}$ Among a large variety of $\mathrm{N}$-containing heterocyclic compounds, those containing Pyrazoles or urazole (1,2,4-triazolidine3,5-dione) moiety have received considerable attention because of their pharmacological properties and clinical applications. ${ }^{6-9}$ 
Considering the above reports and in continuation of our research on multi-component reactions ${ }^{10-14}$, Herein we have researched for threecomponent coupling of aldehydes1, malononitrile 2, and 4-phenylurazole 3 in the presence of $\mathrm{ZrO}_{2}$ nanoparticles to the synthesis of pyrazolo[1,2-a] $[1,2,4]$ triazole-1,3-diones derivatives 4 (Scheme 1).

\section{RESULTS AND DISCUSSION}

To choose optimum conditions, first, the effect of temperature on the rate of the reaction was studied for the preparation of 7-amino-5-(4-chlorophenyl)-1, 2,3, 5-tetrahydro-1, 3-dioxo-2-phenylpyrazolo [1,2-a][1,2,4]triazole-6carbonitrile from the three-component condensation reaction of 4-phenylurazole, malononitrile, and 4-chlorobenzaldehyde under solvent-free conditions (Table 1). At $80^{\circ} \mathrm{C}$, the reaction proceeded smoothly and almost complete conversion of product was observed. Further increase in temperature to, 100 and $120^{\circ} \mathrm{C}$ increased the rate of reaction. Therefore, we kept the reaction temperature as $100^{\circ} \mathrm{C}$ (giving short reaction time and high yield). Next, the study set out to determine optimal amount of nano- $\mathrm{ZrO}_{2}$, the reaction was carried out by varying amount of the catalyst (Table 1). Maximum yield was obtained with $0.02 \mathrm{~g}(0.2 \mathrm{mmol})$ of the catalyst. Further increase in amount of nano- $\mathrm{ZrO}_{2}$, in the mentioned reaction did not has any significant effect on the product yield.

To study the scope of the reaction, a series of aldehydes were employed. The results are shown in Table 2. In all cases, aromatic aldehydes substituted with either electron-donating or electronwithdrawing groups underwent the reaction smoothly and gave the products in good yields. When this reaction was carried out with aliphatic aldehyde such as butanal or pentanal, TLC and ${ }^{1} \mathrm{H}$ NMR spectra of the reaction mixture showed a combination of starting materials and numerous products, the yield of the expected product was very poor.

The compounds $4 \mathbf{a}-\mathbf{j}$ were known compounds and their identity was confirmed by a comparison of their m.p. (Table 2) and their spectral properties with literature data. ${ }^{15-17}$

Although it is not clear how $\mathrm{ZrO}_{2}$ acts as a catalyst for the reaction, on the basis of the surface of metal oxides exhibit both Lewis acid and Lewis base character ${ }^{18,19}$ and according to the literature survey ${ }^{15-17}$, the suggested mechanism for the formation of the products is shown in Scheme 2. First, via a Knoevenagel condensation of malononitrile 1 and arylaldehydes 2 in the presence of $\mathrm{ZrO}_{2} \mathrm{NPs}$ as the catalyst was afforded benzylidenemalononitrile 5 Then, Michael addition of 4-phenylurazole 3 to benzylidenemalononitrile 5 formed intermediate 6 that underwent cyclization and tautomerism affords the corresponding products 4 .

The reusability of the catalyst was tested in the synthesis of 7-amino-5-(4-chlorophenyl)-1,2,3,5tetrahydro-1,3-dioxo-2-phenylpyrazolo[1,2-a][1,2,4] triazole-6-carbonitrile, as shown in Figure 1. The catalyst was recovered after each run, washed with ethanol, dried in an oven at $100^{\circ} \mathrm{C}$ for 15 min. prior to use and tested for its activity in the subsequent run. The catalyst was tested for 4 runs. It was seen that the catalyst displayed very good reusability (Figure 1).

\section{EXPERIMENTAL}

Melting points were determined with an Electrothermal 9100 apparatus. Elemental analyses were performed using a Heraeus $\mathrm{CHN}-\mathrm{O}$ Rapid analyzer. Mass spectra were recorded on a FINNIGAN-MAT 8430 mass spectrometer operating at an ionization potential of $70 \mathrm{eV}$. IR spectra were recorded on a Shimadzu IR-470 spectrometer. ${ }^{1} \mathrm{H}$ and ${ }^{13} \mathrm{C}$ NMR spectra were recorded on Bruker DRX-500 Avance spectrometer at solution in DMSO- $d_{6}$ using TMS as internal standard. The chemicals used in this work were purchased from Fluka (Buchs, Switzerland) and were used without further purification. In all experiments, $\mathrm{ZrO}_{2}(5-25$ $\mathrm{nm}$, Plasma Chem $\mathrm{GmbH}$ ) was used.

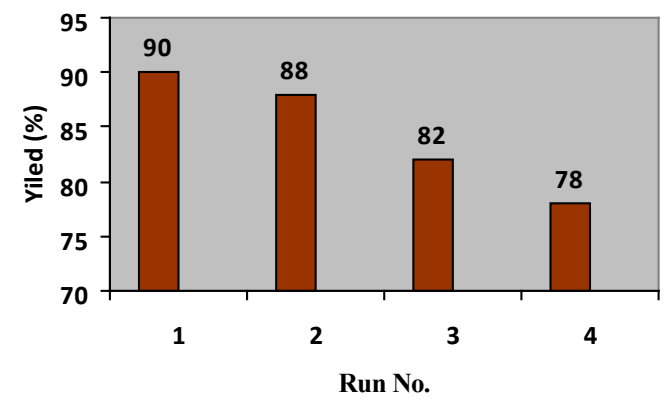

Fig. 1: Reusability of the catalyst 
Table 1: Optimization amount of $\mathrm{ZrO}_{2}$ nanoparticles and reaction temperature for preparation 7-amino-5-(4-chlorophenyl)-1,2,3,5-tetrahydro1,3-dioxo-2- phenylpyrazolo[1,2-a][1,2,4]triazole-6-carbonitrile under solvent-free conditions ${ }^{\mathrm{a}}$

\begin{tabular}{ccccc}
\hline Entry & Catalyst $(\mathrm{g}, \mathrm{mmol})$ & Temp $\left({ }^{\circ} \mathrm{C}\right)$ & Time $(\mathrm{min})$ & Yield $(\%)^{\mathrm{b}}$ \\
\hline $\mathbf{1}$ & $0.01 \mathrm{~g}, 0.1 \mathrm{mmol}$ & 100 & 30 & 72 \\
$\mathbf{2}$ & $0.02 \mathrm{~g}, 0.2 \mathrm{mmol}$ & 100 & 30 & 91 \\
$\mathbf{3}$ & $0.03 \mathrm{~g}, 0.3 \mathrm{mmol}$ & 100 & 30 & 88 \\
$\mathbf{4}$ & $0.04 \mathrm{~g}, 0.4 \mathrm{mmol}$ & 100 & 30 & 88 \\
$\mathbf{5}$ & $0.02 \mathrm{~g}, 0.2 \mathrm{mmol}$ & 120 & 25 & 89 \\
$\mathbf{6}$ & $0.02 \mathrm{~g}, 0.2 \mathrm{mmol}$ & 90 & 40 & 88 \\
$\mathbf{7}$ & $0.02 \mathrm{~g}, 0.2 \mathrm{mmol}$ & 80 & 40 & 80 \\
\hline \hline
\end{tabular}

${ }^{a}$ Reaction conditions: 4-Phenylurazole $(1.0 \mathrm{mmol})$, malononitrile (1.0 mmol), 4-chlorobenzaldehyde $(1.0 \mathrm{mmol})$.

b Isolated yield

Table 2: Three-component reaction of aromatic aldehydes, malononitrile and 4-phenylurazole catalyzed by $\mathrm{ZrO}_{2}$ NPs under solvent-free conditions ${ }^{a}$

\begin{tabular}{c|cccc}
\hline Entry & $\mathrm{Ar}$ & Time $(\mathrm{min})$ & Yield $^{\mathrm{b}}(\%)$ & $\mathrm{mp}\left({ }^{\circ} \mathrm{C}\right)^{(\text {lit })}$ \\
\hline $\mathbf{4 a}$ & $4-\mathrm{Cl}-\mathrm{C}_{6} \mathrm{H}_{4}$ & 30 & 90 & $>220(>221)^{15-17}$ \\
$\mathbf{4 b}$ & $2-\mathrm{Cl}_{-} \mathrm{C}_{6} \mathrm{H}_{4}$ & 35 & 88 & $233(>218)^{15-17}$ \\
$\mathbf{4 c}$ & $4-\mathrm{Br}_{-} \mathrm{C}_{6} \mathrm{H}_{4}$ & 35 & 85 & $>224(>224)^{15-17}$ \\
$\mathbf{4 d}$ & $4-\mathrm{F}_{-} \mathrm{C}_{6} \mathrm{H}_{4}$ & 35 & 89 & $>223(>222)^{15-17}$ \\
$\mathbf{4 e}$ & $2-\mathrm{NO}_{2}-\mathrm{C}_{6} \mathrm{H}_{4}$ & 35 & 87 & $233(>221)^{15-17}$ \\
$\mathbf{4 f}$ & $4-\mathrm{NO}_{2}-\mathrm{C}_{6} \mathrm{H}_{4}$ & 30 & 90 & $220(>218)^{15-17}$ \\
$\mathbf{4 g}$ & $\mathrm{C}_{6} \mathrm{H}_{5}$ & 40 & 86 & $>210(>210)^{15-17}$ \\
$\mathbf{4 h}$ & $3-\mathrm{CN}_{-} \mathrm{C}_{6} \mathrm{H}_{4}$ & 35 & 87 & $226(>225)^{15-17}$ \\
$\mathbf{4 i}$ & $2,4-\mathrm{Cl}_{-}-\mathrm{C}_{6} \mathrm{H}_{3}$ & 30 & 82 & $>200(>200)^{15-17}$ \\
$\mathbf{4 j}$ & $4-\mathrm{CH}_{3}-\mathrm{C}_{6} \mathrm{H}_{4}$ & 40 & 80 & $>217(>217)^{15-17}$ \\
$\mathbf{4 k}$ & ${ }^{2}-\mathrm{C}_{5} \mathrm{H}_{11}$ & 40 & -- & \\
\hline
\end{tabular}

a Reaction conditions: 4-Phenylurazole (1.0 mmol), malononitrile $(1.0 \mathrm{mmol})$, aromatic aldehyde $(1.0 \mathrm{mmol})$ under thermal solvent-free condition at $100{ }^{\circ} \mathrm{C}$.

bIsolated Yield 


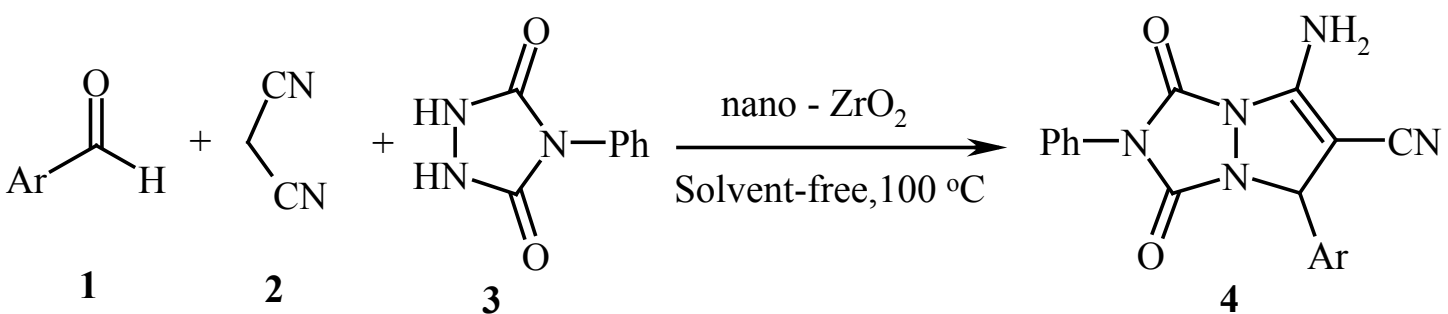

\section{(Scheme 1)}

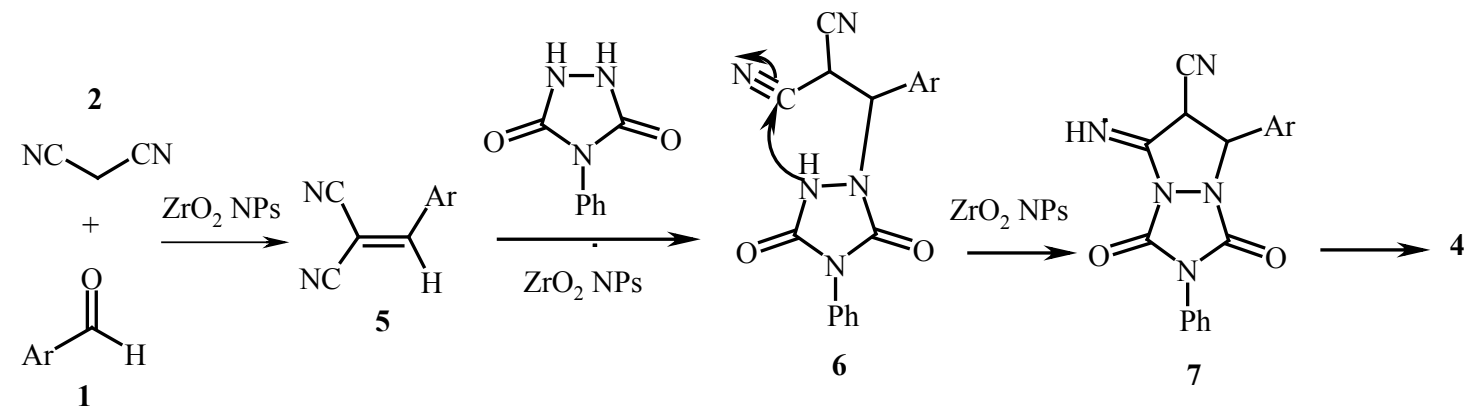

Scheme 2: The proposed mechanism for the synthesis of pyrazolo[1,2-a][1,2,4] triazole-1,3-diones in solvent-free conditions catalyzed by $\mathrm{ZrO}_{2} \mathrm{NPs}(20 \%)$

\section{General procedure}

A mixture of malononitrile $(1.0 \mathrm{mmol})$, aromatic aldehyde $(1.0 \mathrm{mmol})$, 4-arylurazole $(1.0 \mathrm{mmol})$, and nano- $\mathrm{ZrO}_{2}(20 \mathrm{~mol} \%)$ was heated at $100^{\circ} \mathrm{C}$ for $30-40 \mathrm{~min}$. After completion of the reaction as indicated by TLC, the reaction mixture was cooled to room temperature. The solid residue was dissolved in hot ethanol and centrifuged to separate the catalyst. By recrystallization from ethanol, pure products were obtained.

7-amino-5-(4-chlorophenyl)-1,2,3,5tetrahydro-1,3-dioxo-2-phenylpyrazolo[1,2-a][1,2,4] triazole-6-carbonitrile 4a:

White powder $\mathrm{mp}>220 \stackrel{\circ}{\circ}$, yield $90 \%$, IR $(\mathrm{KBr})\left(v_{\max }, \mathrm{cm}^{-1}\right): 1731,1712$ ( CO ester), ${ }^{1} \mathrm{H}$ NMR (500 $\mathrm{MH}_{\mathrm{z}}$, DMSO-d $\left.\mathrm{d}_{6}\right): \delta=6.03(1 \mathrm{H}, \mathrm{s}, \mathrm{CH})$, 7.35-8.35 (11H, m, $\mathrm{H}$-Ar and $\left.\mathrm{NH}_{2}\right) .{ }^{13} \mathrm{C}$ NMR (125.8 $\left.\mathrm{MH}_{\mathrm{z}}, \mathrm{DMSO}-\mathrm{d}_{6}\right): \delta=61.7,63.6,, 116.4,124.2$,
126.7, 128.4, 128.8, 129.2, 129.7, 130.3, 131.0, 131.8, 146.3, 148.0, 150. 7,154. Analyses: Calcd. for $\mathrm{C}_{18} \mathrm{H}_{12} \mathrm{CIN}_{5} \mathrm{O}_{2}: \mathrm{C}, 59.11 ; \mathrm{H}, 3.31 ; \mathrm{N}, 19.15$ Found: C, $59.34 ; \mathrm{H}, 3.12 ; \mathrm{N}, 19.36 \%$.

\section{CONCLUSIONS}

We have developed a simple, efficient, one-pot and green protocol for the synthesis of pyrazolo[1,2-a][1,2,4]triazole-1,3-diones derivatives using nano- $\mathrm{ZrO}_{2}$ as a reusable heterogeneous catalyst under solvent-free conditions. The simplicity, easy workup, as well as safety and reusability of catalyst are advantages of this method.

\section{ACKNOWLEDGEMENTS}

We gratefully acknowledge financial support from the Research Council of Islamic Azad University, Mahshahr branch. 


\section{REFERENCES}

1. Domling, A.; Ugi, I. Angew. Chem. Int. Ed. Engl. 2000, 39, 3168-3210.

2. Pacchioni, G. Surf. Rev. Lett. 2000, 7, 277306.

3. Knight, W. D.; Clemenger, K.; de Heer, W. A.; Saunders, W. A. M.; Chou Y.; Cohen, M. L. Phys. Rev. Lett. 1984, 52, 2141-2143.

4. Kaldor, A.; Cox D.; Zakin, M. R. Adv. Chem. Phys. 1988, 70, 211-261.

5. Gribble, G.W. In Comprehensive Heterocyclic Chemistry II, Vol. 2; A. R. Katriztky, C.W. Rees, , E. F. V. Scriven, Eds.; Elsevier: Oxford, 1996, 207.

6. P.D. Boatman, J. Urban, M. Nguyen, M. Qabar and M. Kahn, Bioorg. Med. Chem. Lett. 2003, 13, 1445-1449.

7. Izydore, R. A.; Bernal-Ramirez J. A.; Singh, P. J. Org. Chem. 1990, 55, 3761-3767.

8. Kiriazis, A.; Ruffer, T.; Jantti ,S.; Lang, H.; Yli-Kauhaluama, J. J. Comb. Chem. 2007, 9, 263-266.

9. Kolb, V. M. ; Dworkin J. P.; Miller, S. L.; J. Mol. Evol. 1994, 38, 549-557.

10. Anaraki-Ardakani, H.; Mosslemin, M.
H.; Anary-Abbasinejad, M.; Shams N.; Mirhosseini, S. H. Arkivoc 2010, 11, 343349.

11. Anaraki-Ardakani, H.; Noei M.; Tabarzad, A.Chinese Chemical Letters 2012, 23, 4548.

12. Anaraki-Ardakani, H.; Noei, M. ; KarbalaeiHarofteh M. ; Zomorodbaksh, S. E-Journal of Chemistry 2012, 9, 2239-2244.

13. Malekpour, M.; Anaraki-Ardakani H.; Noei, M. Journal of Chemical Research 2012, 11, 715-717.

14. Anaraki-Ardakani H.; Charooseai, A. Orient j Chem., 2015, 31, 1455-1460.

15. Azarifar, D.; Yami, R. N. Heterocycles 2010, 81, 2063-2073.

16. Shaterian, H. R.; Moradi, F. Research on Chemical Intermediates 2013, 1, 223-229.

17. Shaterian, H. R.; Azizi, K. Journal of Molecular Liquids 2013, 183, 8-14.

18. Tanabe, K. Solid Acids and Bases, Academic Press, New York, 1970.

19. Zarei Ahmady, A.; Keshavarz, M.; Kardan, M.; Mohtasham, N. Orient j Chem, 2015, 31(1), 1841-1846 